\title{
Exercícios espirituais e parrhesia nos Ensaios de Montaigne
}

\author{
Spiritual exercises and parrhesia in Montaigne's Essays
}

\begin{abstract}
Alexandre Soares Carneiro
Professor assistente, Doutor, Departamento de Teoria Literária da Universidade Estadual de Campinas (Unicamp), Campinas, SP - Brasil, e-mail: alex@iel.unicamp.br
\end{abstract}

\section{Resumo}

Em seus últimos trabalhos, Michel Foucault destacou a importância da parrhesia (libertas, franc-parler, "dizer-verdadeiro") nas práticas filosóficas da Antiguidade, em uma reflexão mais ampla sobre a "espiritualidade", inspirada em grande medida na obra de Pierre Hadot. A noção de parrhesia mostra-se interessante também na abordagem dos Ensaios de Montaigne, nos quais podemos reconhecer uma série de "exercícios espirituais", no sentido dado à expressão por Hadot: práticas, não apenas intelectuais, que visam a efetuar uma transformação no sujeito. O "ensaio", em Montaigne, se apresenta como um exercício de "escrita de si" apoiado na leitura dos antigos, sobretudo dos filósofos do período helenístico. Essa ascese filosófica do gênero ensaístico também interessou a Foucault.

Palavras-chave: Michel de Montaigne. Exercícios espirituais. Parrhesia. Pierre Hadot. Michel Foucault.

\section{Abstract}

In his late work Michel Foucault stressed the importance of parrhesia (libertas, franc-parler, frankness of speech) in the philosophical practices of the Anciens, through a broader 
reflection on "spirituality" inspired chiefly by the work of Pierre Hadot. The notion of parrhesia emerges as an interesting matter also in a approach of Montaigne's Essays, where we can recognize a series of "spiritual exercises", in the sense given to the expression by Hadot: practices, not only intellectual, intended to effect a transformation in the subject who practice them. The "essay", in Montaigne, appears as a "writing of the self" exercise, based upon the reading of ancient philosophers, mainly from the Hellenistic period. This philosophic ascesis in the essay has also called Foucault's attention.

Keywords: Michel de Montaigne. Spiritual exercises. Parrhesia. Pierre Hadot. Michel Foucault.

Il falloit s'enquerir qui est mieux sçavant, non qui est plus sçavant. (ENSAIOS, I, 25, Do pedantismo)

\section{A leitura dos filósofos como exercício espiritual}

Em seus diálogos com Arnold I. Davidson e Jeannie Carlier, o filósofo e historiador da filosofia, Pierre Hadot, especialista no período helenístico, comenta passagens de sua biografia importantes para a definição das principais linhas de sua obra. Nesse contexto registra como a leitura de Montaigne, ainda na juventude, lhe fez descobrir a "estranha natureza humana", natureza de tal forma complexa que "autorizava todas as atitudes: ceticismo e fé, rigor estoico e distensão epicurista". De modo mais decisivo, o texto intitulado "Que filosofar é aprender a morrer" (Ensaios I, 20) teria ajudado-o a criar-se uma imagem da filosofia como "algo distinto de um discurso teórico". Mais recentemente, um outro capítulo lhe chama a atenção, "Da experiência" (III, 13), que inclui uma passagem entre as epígrafes de seu O que é a filosofia antiga? Ali Montaigne define o ato de viver como "a mais ilustre das preocupações". Para Hadot, tal "reconhecimento do valor infinito da vida em si mesma" seria mais uma importante herança do pensamento antigo no autor dos Ensaios (1580), o qual, no fundo, teria 
compreendido muito bem "o sentido da filosofia antiga, sobretudo epicurista" (HADOT, 2001, p. 199-200).

Os Ensaios poderiam ser vistos, portanto, como um momento marcante na história da recepção do pensamento antigo, ao elaborar as heranças mencionadas por um viés alternativo à versão hegemônica, em que o discurso filosófico se desvincula da existência e se autonomiza. Tal como o livro-depoimento de Hadot, a obra de Montaigne dá conta de um percurso não linear, em que a leitura dos filósofos da Antiguidade é como o fio condutor de uma ampla e muito pessoal meditação sobre si e sobre o mundo. A participação nessa "antitradição" de leitura dos antigos incide, assim, na própria possibilidade dessa última constituir-se, com a escrita, em "exercício espiritual", isto é, atividade de criação de novas perspectivas sobre as coisas e sobre a própria atividade intelectual. A parrhesia, diretamente implicada nos principais "modos de vida" e práticas filosóficas da Antiguidade, também foi objeto de considerações por parte de Montaigne, reflexão que interfere no seu propósito de elaborar para si um "modo de escrita" específico, dito "ensaístico".

\section{Os limites da leitura humanista}

Perante os antigos, Montaigne se porta como um leitor humanista na melhor versão, curioso e algo reverente em relação a um cânone pagão renovado, mas estimulado a produzir comentários pessoais aos textos, interligando passagens literárias e reflexões morais, comparando-as entre si e estabelecendo-as como parâmetro na avaliação de eventos modernos e de sua própria conduta moral e intelectual (ver GRAFTON, 1988, p. 307). Na verdade, ao abordar a literatura filosófica da Antiguidade, ele opera um deslocamento importante quando afirma o primado do iudicium sobre a memoria e, tendo a copia rerum et uerborum como ponto de partida, evita limitar o exercício do comentário a um virtuosismo literário, na linha das polêmicas eruditas, por exemplo. Mais propenso a explorar o potencial perturbador dos textos do que a 
conciliar suas contradições, ou a acomodá-los, domesticando-os, à moral cristã e à tradição escolar, os Ensaios se mostram, primordialmente, como o registro pessoal e mesmo idiossincrático de uma experiência de perplexidades, simultaneamente crítica e autocrítica - de onde, costuma-se dizer, vem a importância de seu contato com o pirronismo. ${ }^{1}$

A prática da leitura humanista é assim reorientada no sentido de avivar as aporias e os estranhamentos produzidos por um exercício de julgamento que parte dos textos mas vai além deles. Procedimento decisivo na avaliação de autores (contrapondo Virgílio e Lucrécio, Plutarco e Sêneca, Tito Lívio e Tácito, etc.), o iudicium comparativo será arma, tão contundente quanto afiada, também na abordagem de assuntos "não literários", temas espinhosos como a fé religiosa, a sexualidade ou a própria natureza "instável" do eu racional, ${ }^{2}$ em um procedimento que desestabiliza, por contágio, todo um sistema de crenças paralisantes e categorias simplificadoras (GARAVINI, 1995, p. 64). Advertindo-nos que limitará sua atividade de escrita ao propósito restrito de se dedicar à criação de um ethos privado, ele pode tomar distância dos saberes instituídos e se pronunciar em nome próprio. Os "ensaios" seriam assim um conjunto de julgamentos conjecturais animados, diríamos, por uma forma pessoal de "coragem da verdade", tópico recorrentemente invocado nas considerações que faz sobre sua própria escrita, quando reafirma a exigência da franchise (dire vrai, liberté, etc.), uma das virtudes que reconhece em seu principal modelo, Sócrates. ${ }^{3}$

\section{A escrita como exercício espiritual: a exigência da franqueza}

Esse lógos crítico que no seu exercício contínuo tem algo de "ascético", também poderia ser descrito, na tradição cética (pirrônica), como "terapêutico", pois visaria, em última análise, à ataraxia, ${ }^{4}$ télos que coinci-

\footnotetext{
1 Miguel Granada (2001, p. 14) fala da "grande distance qui existe entre l'épistémologie sceptique et la position essentiellement dogmatique de la culture humaniste, poursuivant sur ce point la traditon médiévale, même avec des modifications".

2 Ver, por exemplo, III, 5 ("Sobre versos de Virgílio"); III, 6 ("Dos cochos"); e Il, 12 ("Apologia de Raymond Sebond").

3 A parrhesia socrática é abordada no capítulo III, 12 ("De la phisionomie"). Análises da parrhesia socrática se encontram nos últimos cursos de Foucault $(2008 ; 2009)$.

4 Sobre a terapêutica pirrônica, ver Voelke (1993).
}

Rev. Filos., Aurora, Curitiba, v. 23, n. 32, p. 113-129, jan./jun. 2011 
de com o da escola epicurista, na qual Foucault identifica modalidades específicas de parrhesia, a partir de um tratado de Filodemo. ${ }^{5}$ Já sua organização em exercício notacional permite aproximações com práticas, sobretudo estoicas, de "escrita de si" (como nas cartas de Sêneca ou nos Pensamentos de Marco Aurélio (ver FOUCAULT, 2006a). Em Montaigne, um análogo possível com tais formas de exercício é sugerido no brevíssimo capítulo "Da ociosidade" (I, 8). Alegando propósitos eminentemente pessoais para a escrita de seus textos, o autor descreve suas digressões como "quimeras e monstros fantásticos" que o espírito ocioso lhe produziu, "sem ordem e sem propósito", a partir de seu retiro da vida pública, quando esperava gozar de um otium mais produtivo e grave:

parecia-me não poder fazer maior favor a meu espírito do que deixá-lo, em plena ociosidade, entreter a si mesmo, fixar-se e repousar em si; e esperava que doravante ele o pudesse fazer mais facilmente, tendo se tornado, com o tempo, mais ponderado e grave. Mas descubro [...] que, ao contrário, imitando o cavalo fugido, ele dá a si mesmo cem vezes mais trabalhos do que assumia por outrem; e engendra-me tantas quimeras e monstros fantásticos, uns sobre os outros, sem ordem e sem propósito, que para examinar com vagar sua inépcia e estranheza comecei a registrá-los por escrito, esperando com o tempo fazer que se envergonhe de si mesmo por causa deles (MONTAIGNE, 2002, p. 45-46).

A escrita serviria então para expor seu espírito à correção, ao exibir, à luz da própria contemplação, a "inépcia e estranheza" de tais fantasias. No entanto, essa exposição de erros, que lembra tanto a "confissão" epicurista como a "crítica das representações" estoicas, é singular e um tanto irônica, já que, ao longo dos capítulos, tais "quimeras" terminam por dar o testemunho não de uma inépcia individual, mas daquela "estranha natureza humana" que Montaigne, ao modo pirrônico,

5 "A parrhesia, diz Filodemo, faz realmente pensar [...] na prática do médico. Aliás, ele desenvolve o paralelismo entre a parrhesia filosófica e a prática médica. A parrhesia, diz ele, é um socorro (boétheia...), é uma therapeía" (FOUCAULT, 2004, p. 469). A cura (da alma) exige a exposição dos sintomas e más condutas: "qui veut guerir de l'ignorance, il faut la confesser", dirá Montaigne em III, 11 ("Des boiteux"). 
inclina-se a acolher e pôr à prova. ${ }^{6}$ Como aponta Merleau-Ponty (1960, p. 320) em sua leitura dos Ensaios, o ceticismo tem duas faces: "ele significa que nada é verdade, mas também que nada é falso. Ele rejeita como absurdas todas as opiniões e todas as condutas, mas nos retira, com isso, os meios de rejeitar qualquer uma como falsa". As fantasias confessadas, liberadas, podem ser purgadas ou, alternativamente, conquistar o status de opinião de algum peso, ganhando cidadania intelectual e animando, em pé de igualdade com respeitáveis sentenças dos filósofos, uma espécie de conversação que tenta estabelecer consigo.

Além disso, ao oferecer-se à leitura pública, tal conversação privada, à parte a dimensão "ascética", de "exercício de si", deve instituir procedimentos retórico-literários específicos, envolvendo, em sua problematização, a relação com o outro por meio da escrita. A liberdade da palavra, que amplia os limites da fantasia e o alcance do julgamento, faz a oferenda de seus ganhos na leitura. Sua reivindicação de franchise no nível pessoal lhe permite versar sobre o que quer que seja, e tudo expor ao crivo do julgamento, liberado de antemão de qualquer censura, tratando-se, afinal, de meras fantasias privadas, sem consequências senão para ele mesmo. Isso é certo, mas elas têm claros apelos, também, para o leitor, ao menos aquele atraído por uma escrita rica e variada como a dos Ensaios. Na feição "monstruosa" desses escritos combinam-se, de certo modo, uma ética da veracidade, uma retórica da sedução e uma estética da desorganização, o que permite que sejam propostas ao leitor como um lugar de reconhecimento, deleite e benevolência, em que pesem sua peculiaridade e seu teor, maior ou menor, de escândalo. ${ }^{7}$

6 Pierre Hadot (1997, p. 95) descreve a escrita "ensaística" de Marco Aurélio como exercício espiritual, atividade de recuperação do princípio racional que se apaga na rotina: "aussi se succèdent les essais nouveaux de rédaction, les reprises des mêmes formules, les variations sans fin sur les mêmes thèmes - ceux d'Épictète. Il s'agit de réactualiser, de rallumer, de réveiller sans cesse un état intérieur qui risque sans cesse de s'assoupir et de séteindre. Toujours, à nouveau, il s'agit de remettre en ordre un discours intérieur qui se disperse et se dilue dans la futilité et la routine". Em Montaigne, tal "ordem" é "movente", traço incontornável da natureza humana.

7 Ver III, 5: "je dy vray, non pas tout mon saoul, mais autant que je l'ose dire; et l'ose un peu plus en veillissant". Sobre a "eunoia" epicurista, vide adiante. 


\section{0 "parler naif" e o decoro "cômico e privado"}

Embora excessivamente visitado, um outro texto ilustra de modo ainda mais interessante o problema da passagem de uma "ascese" privada (seu registro pessoal autocrítico) ao âmbito público, propondo, segundo um protocolo "civilizado", as condições para um intercâmbio o mais livre possível. A advertência "Ao leitor", que abre o Livro I, é uma espécie de convite a nós dirigido segundo o lugar-comum da modéstia afetada, incitando-nos a aproximar daquele espaço "doméstico e privado" em que está assegurada a liberdade da palavra. Novamente uma passagem retórica de rigueur, mas também passagem ritual (do público ao privado, e vice-versa), lugar liminar de acolhimento a um leitor que será conduzido (se lhe aprouver) a um universo que se assume como despretensioso, mas que se dará a perceber em outro tom - não o da modéstia, mas o da ousadia. Tal liberdade de palavra e pensamento pressupõe tanto a quebra do decoro formal como a instituição de um outro decoro, que delimita e ao mesmo tempo viabiliza o propósito crítico que assume.

Tais considerações, como indicamos, nos colocam diante do complexo tema da retórica em Montaigne (LESTRINGANT, 1985) e da antiga aliança polêmica dela com a parrhesia - descrita como figura de retórica em Quintiliano. Como todos irão se lembrar, essas poucas linhas de abertura começam com uma interpelação ao leitor, a quem é imediatamente apresentado um "livro de boa fé" - isto é, que nos adverte desde o início sobre seu fim meramente "doméstico e privado". Tal obra não obedeceria ao desejo de obter o "favor do mundo" para o autor, o que exigiria uma apresentação mais ornamentada e estudada. O que promete, ao contrário, é um autorretrato em sua "maneira simples, natural e ordinária", garantia de uma fidelidade a si. E avança: "meus defeitos aí se lerão ao vivo, assim como minha forma ingênua (ou natural: nä̈ve), tanto quanto mo permitiu a reverência pública". Se ele estivesse entre aqueles nativos que dizem viver "sob a doce liberdade das primeiras leis da natureza", teria de bom grado (ele nos assegura) se pintado "todo inteiro e todo nu". 
A ornamentação, essa exigência da eloquência pública e da vida civilizada, surge como tolhimento de um bem viver natural, associado a uma expressão livre e plena. Contudo, como se sabe, mesmo para rejeitar a retórica precisa-se dela (MATHIEU-CASTELLANI, 2000, p. 28; COMPAGNON, 1985). A ironia autodepreciativa serve, neste contato inaugural, para nos atrair e ao mesmo tempo indicar os parâmetros de acesso a um texto que busca expor seus vínculos com uma vida particular. Igualmente, o sermo humilis de um "estilo cômico e privado",, 8 simples e irregular, é o que melhor corresponderia à vida "sem glória" de que vai apresentando detalhes; vida "popular e privada", mas que seria espelho da "condição humana", segundo a passagem célebre, ${ }^{9}$ e assim portadora de interesse, e mesmo grandeza, em seus múltiplos temas e abordagens; e que, sobretudo, servirá a estes de caução necessária e suficiente. Como diz Merleau-Ponty (1960, p. 324) no texto já citado:

espantamo-nos que ele tenha desejado falar até os detalhes sobre seu humor e seu temperamento.

É que para ele toda doutrina, separada daquilo que nós fazemos, ameaça ser mentirosa, e ele imagina um livro em que, por uma vez ao menos, se encontrem expressos não apenas idéias, mas a própria vida em que elas aparecem, e que lhes modifica o sentido.

Tal exigência de veracidade vincularia a busca da verdade à sua expressão direta, "veemente e brusca", em um vínculo parresiástico presente, de uma maneira geral, na experiência filosófica da Antiguidade; e, de uma maneira radical, no modo de vida dos cínicos. Como mostrou Foucault (2009), a parrhesia coabita neles com uma afirmação ostensiva da vida natural. Caberia, aliás, neste

8 Ver I, 40 ("Considérations sur (icéron"): "J'ay naturellement un stile comique et privé, mais c'est d'une forme mienne, inepte aux negotiations publiques, comme en toutes façons est mon langage: trop serré, desordonné, couppé, particulier". "Estilo cômico" significa aqui "registro adequado às comédias". Ver MATHIEU-CASTELLANI (2000, p. 81). Sobre os sentidos de naiveté, ver ATKINSON (1995).

9 "Je propose une vie basse et sans lustre, c'est tout un. On attaché aussi bien toute la philosophie morale à une vie populaire et privé qu'à une vie de plus riche étoffe; chaque homme porte en soi la forme entière de l'humaine condition" (III, 2, "Du repentir"). 
quadro, incluir a literatura (neo)cínica entre as heranças antigas (e renascentistas) de Montaigne, o que confere um significado especial à alusão aos costumes naifves (de natious) dos tupinambás, sobre os quais especulará no capítulo I, 31 (“Dos canibais"). O modo de vida cínico é o subtexto de seu interesse pela vida dos indígenas, em uma assimilação daquela escola ao estoicismo, certamente mais palatável à "reverência pública". As anedotas sobre Diógenes e outros cínicos presentes nos Ensaios (sobretudo na sua última versão) reforçam, de todo modo, a valorização dessa seita, vista como "plus franche" quando comparada à peripatética "plus civile", ${ }^{10}$ segundo os pólos sugeridos, no texto dirigido "Ao leitor", que comentamos: "lei da natureza" e "reverência pública".

Procedimentos dessa natureza serão mobilizados para viabilizar um experimento de escrita que busca meios de tornar legível, na instância do texto, a intuição, sugerida a Montaigne pelos antigos, de que a prática filosófica autêntica faz um apelo importante não só ao lógos como também ao bios. Paralelamente, há a constituição, como vimos, de um modelo negativo de composição, perante o qual declara sua contínua desconfiança - as práticas oratórias que dominaram a formação escolar humanista, voltadas para o discurso público e de aparato, emanado em uma persona solene imbuída de convicções e de pretensões cívicas. A retórica, essa "vertu parlière", estabelecida de forma patente como apenas mais um moyen de parvenir, não tem lugar na experiência filosófica autêntica - interior, meditativa e pessoal -, e aproxima-se da garrulitas incriminada por Plutarco. Caberá tomar o partido de uma "vraye et naifve philosophie" contra uma filosofia "ostentatrice et parlière" (I, 39, "De la solitude").

Na verdade é bastante viável aproximar Montaigne, por esse viés, de uma corrente neo-estoica que valoriza outro modelo de composição, sob a influência de tratados, como o Ciceronianus de Erasmo, de que

10 Ver CLEMENT (2005). Tradições arcaicas sobre "bons selvagens" teriam ajudado na constituição do cinismo grego, segundo Romm (2007). Diógenes Laércio (VI, 96) narra que o cínico Crates, para expressar seu modo de vida, teria se apresentando nu diante de Hipárquias, que Ihe propunha casamento (FOUCAULT, 2009, p. 159). 
incorpora uma passagem em um capítulo abertamente pedagógico. ${ }^{11}$ Comentando as Epistolae ad Lucilium, Foucault destaca que a parrhesia estoica é apresentada por Sêneca como uma forma especial de eloquência. Segundo a lição oferecida pela carta 40, no discurso do filósofo, trata-se antes de mostrar (ostendere) o que se experimenta (quod sentiam) do que falar (loqui). Dentro dos preceitos da paradósis, o discurso da verdade deve ser simplex, isto é, transparente: "que diga o que tenha a dizer, que não tente vesti-lo, cobri-lo, e assim mascará-lo, quer com ornamentos, quer com uma dramaticidade qualquer" (FOUCAULT, 2004, p. 487-490).

No Renascimento, como ressalta Marc Fumaroli (1980), ${ }^{12}$ tal princípio oratório fundamenta um modelo de eloquência também prestigiado (ou seja, aprendido e exercitado), que polemiza com a vertente neociceroniana, afirmando a prioridade da res sobre as verba. Ele assinala, ainda, que a eloquência específica das cartas de Sêneca, de que Montaigne claramente se impregna, é compatível com a revalorização seiscentista do discurso convivial, a conversação filosófica temperada com o sal mundano, o sermo utilizado e tematizado por Cícero e Aulo-Gélio e recuperado por inúmeros cultores do diálogo literário, de Plutarco a Castiglione. Simpático ao caráter privado e contingente da conversação "civil", Montaigne, ao tematizar a experiência do diálogo, destaca sua qualidade filosófica mais exigente, em capítulo descrito por Fumaroli (2004) como seu “discurso do método". Ele ajudaria a distinguir aspectos importantes dessa forma literária nova, inclassificável, em que o recuo a uma dimensão "simples", "baixa" e "nua" da experiência permite o exercício das partes mais nobres da "humaine condition". A referência à Antiguidade aqui também o auxiliará em uma abordagem da "conferência" como "exercício do espírito".

11 "De l'institution des enfants" (I, 26), com a famosa passagem tirada de Erasmo: "le parler que j'ayme, c'est un parler simple et naif, tel sur le papier qu'à la bouche; un parler succulent et nerveux, court et serré, non tant delicat et peigné comme vehement et brusque", ver FRIEDRICH (1968, p. 96) e DEFAUX (1987, p. 43).

12 Fumaroli (1980, p. 59-60), comentando a carta 40, realça analogias com os Ensaios. "Delivrée de sa dépendance vis-à-vis de la foule, l'éloquence selon Sénèque se dépouille des savants effets d'optique, de la théâtralisation du discours químplique un public. Elle s'enracine non dans la subjetivitélivrée à elle-même, mais dans une intérioritéen quête de la sagesse. Et elle sadresse, dans l'amitié et l'ouverture de coeur, à une autre intériorité fraternelle".

Rev. Filos., Aurora, Curitiba, v. 23, n. 32, p. 113-129, jan./jun. 2011 


\section{A "conferência", exercício do espírito (Ensaios, III, 8)}

Miscelânea humanista de leituras, meditação de caráter terapêutico, mimese de conversação graciosa, animada por reflexões de Sêneca, Plutarco, Sexto Empírico, moralistas, historiadores e poetas, os Ensaios aproximam os exercícios literários e outras práticas "humanistas" aos "exercícios espirituais" da tradição helenística, quando se propõem a recuperar destes a raiz socrática, zetética, comum. ${ }^{13}$ Fazendo com que se imponha, em meio à multiplicidade de eventos e leituras, o exame de um Eu singular, seus textos parecem assimilar-se ao exercício meditativo ao modo Marco Aurélio, isto é, dirigidos "a si mesmo". Mas, como notamos, são reflexões que se dão a comunicar e que, semeadas de apóstrofes ao leitor, propõem-lhe uma interlocução provocativa, por meio de paradoxos, zombarias, confissões, desvios, alusões, anedotas e outros recursos de efeito, embora sempre reivindicando a intenção de manter-se leal à sua própria fala. ${ }^{14}$ Assumindo um tom antiacadêmico e invocando de modo consciente exemplos da Antiguidade, "A arte da conferência" (III, 8) permite articular o problema da interlocução ao tema clássico da amizade como lugar da verdade, fonte de prazer e teste rigoroso do verdadeiro diálogo.

Descrita como "o mais proveitoso e natural exercício de nosso espírito" (grifo nosso), esse debate tenso, feito a dois (e não no grupo da "conversação civil" humanista) desponta como "a prática mais doce de nossa vida". Condição para este exercício é a fala franca:

assim, as contradições dos julgamentos não me ofendem nem me alteram, apenas me despertam e me exercitam. Fugimos da correção, deveríamos oferecer-nos e nos expormos a ela, principalmente quando vem na forma de conversação, e não de aula [conférence, non de régence] [...] Eu toleraria ser contestado rudemente pelos meus amigos. 'És um tolo, estás deliran$\mathrm{do}^{\prime}$. Aprecio que entre homens de brio nos expressemos corajosamente,

13 Ver Stock (2008, p. 51) e Fumaroli (2004). Sobre o elenchos como "prova" que revela o valor de um homem, em Sócrates, ver BRISSON (2005, p. 71) e também HADOT (1999, p. 54). Sobre o capítulo III, 8, ver também PÉRIGOT (2002).

14 Ver Tournon (2004), sobretudo, capítulo V, "A escrita dos Ensaios ou 0 apelo ao leitor". Contrapor, no entanto, com 0 que diz Defaux (1987). Sobre os recursos retórico-literários presentes nos Ensaios (entre os quais a libertas), ver MathieuCastellani $(2000$, p. 29). 
que as palavras vão aonde vai o pensamento. Precisamos fortalecer o ouvido e endurecê-lo contra esta fragilidade do tom cerimonioso das palavras. Aprecio uma convivência e uma familiaridade forte e viril, uma amizade que se compraza na rudeza e no vigor de seu comércio, como o amor nas mordidas e nos arranhões sangrentos. Ela não é suficientemente vigorosa e generosa se não for provocativa, se for civilizada e artificial, se evitar o confronto e tiver um comportamento contrafeito [...]. No entanto é certamente difícil atrair para isto os homens de meu tempo: eles não têm ânimo (courage) para corrigir porque não têm ânimo (courage) para suportar ser corrigidos, e falam, na presença uns dos outros, sempre com dissimulação (MONTAIGNE, 2001, p. 207-209).

Sabemos, a partir de Hadot, que entre as formas de "exercício espiritual" da Antiguidade o diálogo tem lugar especial. Nele, a dimensão do interlocutor é capital. "Ela impede o diálogo de ser uma exposição teórica e dogmática e o submete a ser um exercício concreto e prático", pois se trata "de conduzir o interlocutor a uma certa atitude mental: é um combate, amistoso, mas real". A meditação solitária estaria assim intimamente ligada ao diálogo e vice-versa; o próprio diálogo socrático aparece como "um exercício espiritual praticado em comum, que convida ao exercício espiritual interior" (HADOT, 2002, p. 43). Desse ideal socrático de exercício a dois, "forma de vida" que dá sentido ao discurso, o ensaio aspiraria a ser, portanto, um correspondente escrito, "forma de escrita" que tenta, como os logoi sokratikoi, recuperar as tensões, desvios e digressões da experiência filosófica, com seu apelo a si mesmo e ao outro, segundo uma ética da transparência. ${ }^{15}$

\section{Considerações finais: 0 ensaio, "corpo vivo da Filosofia" (Foucault)}

As formulações de Foucault sobre a parrhesia a mostram implicada na ética antiga do "cuidado de si", a qual, longe de se apresentar como

15 Sobre a parrhesia na dialética socrática, ver Hadot $(1999$, p. 99). Zalloua $(2003,2005)$ aborda os Ensaios tendo em conta Hadot e a parrhesia segundo Foucault. 
individualista, fundamenta-se numa experiência social. ${ }^{16}$ A parrhesia epicurista, por exemplo, se insere no universo da amizade entre mestres e discípulos, no ambiente das escolas filosóficas. Ali, a "prática da palavra livre por parte do mestre deve ser tal que sirva de incitação, de suporte e de ocasião aos alunos que, também eles, terão a possibilidade, o direito, a obrigação de falar livremente". E essa palavra livre "aumentará entre eles a eunoia (a benevolência) ou ainda a amizade" (FOUCAULT, 2004, p. 470). De modo mais radical, na parrhesia cínica, a ascese do filósofo representará a conquista de uma liberdade individual que se manifesta enquanto escândalo público, expressão do primado da physis sobre o nomos (GOULETCAZÉ, 1986; FOUCAULT, 2009, p. 155). O modo de vida cínico ampara-se em gestos de transgressão, mas também na palavra viva, arma utilizada na praça pública e fomentadora de uma literatura de intervenção, como diatribes, cartas e aforismos, e de gêneros (em geral cômicos ou satíricos), como o elogio paradoxal e a sátira menipeia, recuperados no século XVI (MARTÍN GARCÍA, 2008; CLEMENT, 2005, p. 187).

Considerando as particularidades históricas desse período, uma perspectiva interessante seria recuperar as reflexões de Montaigne sobre o lugar cívico da palavra franca, em confronto com as justificativas para a dissimulação política, presentes no capítulo de abertura do Livro III dos Ensaios ("Do útil e do honesto"). Nesse marcante texto, uma sentença sobre a parrhesia (Un parler ouvert ouvre un autre parler et le tire hors, comme fait le vin et l'amour) sugere suas virtudes "epicuristas" em um universo dominado por um árido confronto entre o pragmatismo "maquiavélico" e o rigor estoico. ${ }^{17}$ A aproximação "política" mais interessante, no entanto, diz respeito à própria escrita ensaística. Exigência invocada na passagem sinuosa do discurso interior (privado) à manifestação pública, o "dizer-verdadeiro" montaigniano incide na definição de uma forma de conhecimento compatível com o "penser

16 Sobre a relação parrhesia/áskesis (na constituição do sujeito como "sujeito de verediç̧ão"), ver Foucault (2004, p. 449). Sobre o "trabalho de modificação do seu próprio pensamento e dos outros", como a "razão de ser do intelectual", Foucault (2006b, p. 248).

170 capítulo III, 13 ("De la experience") aborda a clássica oposição entre parrhesia e adulação no convívio com os príncipes. Sobre a dimensão política da "conversação" e da "conferência" nos séculos XVI e XVII, ver Fumaroli (1994; 2001) e Dubail (1999). 
autrement" aspirado por Foucault. Em ambos os casos, a escrita assume a dupla vocação de autorreflexão e intervenção, aliadas inseparáveis na desestabilização das disciplinas instituídas para o pensamento.

A parrhesia integra a poiesis do ensaio, enquanto modo de escrita que tenta atrair um leitor capaz de responder a um desafio intelectual vivo, que não perde de vista a experiência, nunca concluída, de autotransformação a ele vinculada. A libertas invocada nos Ensaios incita uma liberação diante dos dogmas de escola (já lembrava Hadot) enquanto prolongamento de um exercício livre de sképsis; bem o percebeu Emerson, que quis acrescentar-lhes novos capítulos, novos volumes, em seu próprio nome. Tal liberdade é condição e consequência de um rigoroso exercício de exame, julgamento e autoexperimentação, traços que distinguem os melhores cultores do gênero.

Diante disso, e deixando de lado a questão do "dizer-verdadeiro" que se invoca a propósito de suas intervenções públicas (GROS, 2004), lembro finalmente de certas preocupações particulares que surgem na escrita do "último Foucault", aquele que se interessou pela cura sui na filosofia antiga. Um Foucault ensaísta, ou que ao menos desejou sê-lo, e que, ao introduzir seu primeiro livro dedicado ao período (o volume II da História da sexualidade), interrogou-se sobre o lugar do ensaio na "prática filosófica" contemporânea, invocando justamente seu lado "ascético", de "exercício espiritual":

mais qu'est-ce donc la philosophie aujourd'hui - je veux dire l'activité philosophique - si elle n'est pas le travail critique de la pensée sur elle-même? Et si elle ne consiste pas, au lieu de légitimer ce qu'on sait dejà, à entreprendre de savoir comment et jusqu'où il serait possible de penser autrement? [...]. L'essai' - qu'il faut entendre comme épreuve modificatrice de soi-même dans le jeu de verité et non comme appropriation simplificatrice d'autrui à des fins de communication - est le corps vivant de la philosophie, si du moins celle-ci est encore maitenant ce qu'elle était autrefois, c'est à dire, une 'ascèse', un exercice de soi, dans la pensée (FOUCAULT, 1984, p. 14-15).

\section{Referências}

ATKINSON, J. B. Montaigne et Naïveté. In: BERVEN, D. Language and meaning. New York; London: Word Study in Montaigne's Essais, 1995. 
BRISSON, L. Introduction. In: PLATON. Apologie de Socrate. Criton. Paris: Flammarion, 2005.

CLEMENT, M. Diogène dans les Essais ou le corps impudique. In: CLEMENT, M. Le cynisme a la Renaissance d'Erasme a Montaigne. Suivi de 'Les Epistres de Diogenes' (1546). Genève: Droz, 2005.

COMPAGNON, A. Montaigne ou la parole donnée. In: LESTRINGANT, F. (Ed.). Rhétorique de Montaigne. In: ACTES DU COLLOQUE DE LA SOCIÉTÉ DES AMIS DE MONTAIGNE, 1., 1984, Paris. Annales... Paris: Honoré Champion, 1985.

DEFAUX, G. L'impossible présence: Montaigne et la représentation de l'autre. In DEFAUX, G. Marot, Rabelais, Montaigne: L'écriture comme présence. Genève: Slatkine, 1987.

DUBAIL, I. De la contentio au sermo, ou le triomphe du discours privé dans la controverse à la fin des guerres de religion. Libertinage et philosophie au XVIIe siècle, vol. 3: le public et le privé. Journée d'étude organisée par A. McKenna et P.-F. Moreau. Saint-Etienne: Publications de l'Université de Saint-Etienne, 1999.

FOUCAULT, M. Histoire de la sexualité II. l'usage des plaisirs. Paris: Gallimard, 1984.

FOUCAULT, M. A hermenêutica do sujeito. São Paulo: Martins Fontes, 2004.

FOUCAULT, M. A escrita de si. In: FOUCAULT, M. Ditos e escritos V. Rio de Janeiro: Forense Universitária, 2006a. p. 144-162.

FOUCAULT, M. O cuidado com a verdade. In: FOUCAULT, M. Ditos e escritos V. Rio de Janeiro: Forense Universitária, 2006b. p. 240-251.

FOUCAULT, M. Le gouvernement de soi et des autres. Cours au Collège de France.1982-1983. Paris: Gallimard; Seuil, 2008.

FOUCAULT, M. Le courage de la vérité: le gouvernement de soi et des autres II. Cours au Collège de France, 1983-1984. Paris: Gallimard; Seuil, 2009.

FRIEDRICH, H. Montaigne. Paris: Gallimard, 1968. 
FUMAROLI, M. L'âge de l'eloquence. Rhétorique et «res literaria» de la Renaissance au seuil de l'époque classique. Paris: Droz, 1980.

FUMAROLI, M. La conversation. In: FUMAROLI, M. Trois institutions litteraires. Paris: Gallimard, 1994. p. 111-210.

FUMAROLI, M. Les Essais de Montaigne: l'éloquence du for intérieur. In: FUMAROLI, M. La diplomatie de l'esprit. Paris: Gallimard, 2001. p. 125-161.

FUMAROLI, M. O discurso do método de Montaigne. In: PASCAL, B. A arte de persuadir: precedida de A arte da Conferência de Montaigne. São Paulo: Martins Fontes, 2004.

GARAVINI, F. Les structures de la prudence destructrice. In: GARAVINI, F. Itinéraires à Montaigne. Jeux de textes. París: Honoré Champion, 1995. p. 55-65.

GOULET-CAZE, M-O. L'ascèse cynique: un commentaire de Diogène Laërce VI 70-71. Paris: Vrin, 1986.

GRAFTON, A. El lector humanista. In: CHARTIER, R.; CAVALLO, G. Historia de la lectura en en mundo occidental. Madrid: Taurus, 1998. p. 281-328.

GRANADA, M. Apologétique platonicienne et apologétique sceptique: ficin, Savonarole, Jean-François Pic de la Mirandole. In: MOREAU, P-F. Le scepticisme aux XVIe et XVIIe siècles: le retour des philosophies antiques à l'Âge classique, t. II. Paris: Albin Michel, 2001. p. 11-47.

GROS, F. (Org.). Foucault: a coragem da verdade. São Paulo: Parábola, 2004.

HADOT, P. Introduction aux “Pensées” de Marc Aurèle. Paris: Fayard, 1997.

HADOT, P. O que é a filosofia antiga? São Paulo: Loyola, 1999.

HADOT, P. La philosophie comme manière de vivre: entretiens avec Jeannie Carlier et Arnold I. Davidson. Paris: Albin Michel, 2001.

HADOT, P. Exercices spirituels et philosophie antique. Paris: Albin Michel, 2002.

LESTRINGANT, F. (Ed.). Rhétorique de Montaigne. In: ACTES DU COLLOQUE DE LA SOCIÉTÉ DES AMIS DE MONTAIGNE, 1., 1984, Paris. Annales... Paris: Honoré Champion, 1985.

MARTÍN GARCÍA, J. A. Los filósofos cínicos y la literatura moral serioburlesca. Madrid: Akal, 2008. v. 2. 
MATHIEU-CASTELLANI, G. Montaigne ou la verité du mensonge. Paris: Droz, 2000.

MERLEAU-PONTY, M. Lecture de Montaigne. In: MERLEAU-PONTY, M. Éloge de la philosophie. Paris: Gallimard, 1960. p. 112-144.

MONTAIGNE, M. de. Ensaios. São Paulo: Martins Fontes, 2001. v. III. MONTAIGNE, M. de. Ensaios. São Paulo: Martins Fontes, 2002. v. I.

PÉRIGOT, B. Montaigne, de l'art de conférer (III, 8): de la dispute à l'essai. In: GLAUDES, P. (Ed.). L'essai: métamorphoses d'un genre. Toulouse: Presses Universitaires do Mirail, 2002. p. 157-186.

ROMM, J. Cinocéfalos e bons selvagens. Cinismo antes dos cínicos? In: GOULET CAZÉ, M. O.; BRACHT BRANHAM, R. (Org.). Os cínicos: o movimento cínico na Antiguidade e o seu legado. São Paulo: Loyola, 2007. p. 137-152.

STOCK, B. Lire, une ascèse? Lecture ascétique et lecture esthétique dans la culture occidentale. Grenoble: Jêrome Millon, 2008.

TOURNON, A. Montaigne. São Paulo: Discurso, 2004.

VOELKE, A-J. Soigner par le logos: la thérapeutique de Sextus Empiricus. In: VOELKE, A-J. La philosophie comme thérapie de l'âme: études de philosophie hellénistique. Fribourg; Paris: Fribourg Academic Press; Editions du Cerf, 1993, p. 107-126.

ZALLOUA, Z. Montaigne's de l'art de conférer: conference as an act of friendship. Philological Quarterly, v. 82, n. 1, p. 24-37, 2003.

ZALLOUA, Z. Montaigne and the ethics of skepticism. Charlottesville: Rookwood Press, 2005.

Recebido: 10/09/2010

Received: 09/10/2010

Aprovado: $30 / 11 / 2010$

Approved: 11/30/2010 